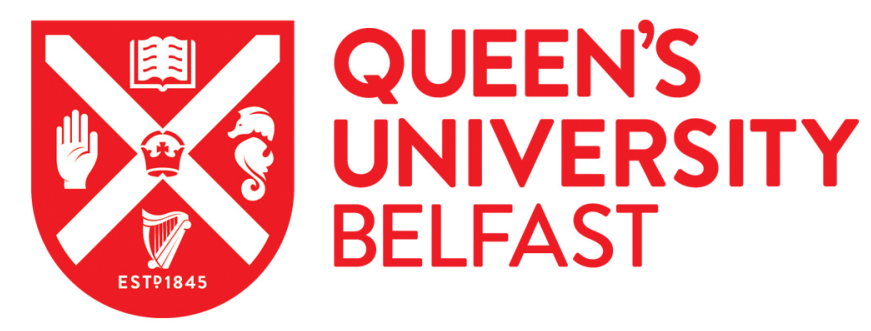

\title{
Effect of community screening on the demographic makeup and clinical severity of glaucoma patients receiving care in urban China
}

\author{
Liang, Y., Jiang, J., Ou, W., Peng, X., Sun, R., Xu, X., Yang, J., Hu, C., Ye, C., Congdon, N., \& Lu, F. (2018). \\ Effect of community screening on the demographic makeup and clinical severity of glaucoma patients receiving \\ care in urban China. American Journal of Ophthalmology, 1-20. https://doi.org/10.1016/j.ajo.2018.07.013
}

Published in:

American Journal of Ophthalmology

Document Version:

Peer reviewed version

Queen's University Belfast - Research Portal:

Link to publication record in Queen's University Belfast Research Portal

Publisher rights

Copyright 2018 the authors.

This is an open access article published under a Creative Commons Attribution License (https://creativecommons.org/licenses/by/4.0/), which permits unrestricted use, distribution and reproduction in any medium, provided the author and source are cited.

\section{General rights}

Copyright for the publications made accessible via the Queen's University Belfast Research Portal is retained by the author(s) and / or other copyright owners and it is a condition of accessing these publications that users recognise and abide by the legal requirements associated with these rights.

Take down policy

The Research Portal is Queen's institutional repository that provides access to Queen's research output. Every effort has been made to ensure that content in the Research Portal does not infringe any person's rights, or applicable UK laws. If you discover content in the Research Portal that you believe breaches copyright or violates any law, please contact openaccess@qub.ac.uk. 


\section{Accepted Manuscript}

Effect of community screening on the demographic makeup and clinical severity of glaucoma patients receiving care in urban China

Yuanbo Liang, MD, PhD, Junhong Jiang, MD, Wen Ou, MD, Xianyao Peng, MD,

Ruizhu Sun, MD, Xiang Xu, MD, Juanyuan Yang, MD, Cheng Hu, MD, Cong Ye, MB,

$\mathrm{PhD}$, Nathan Congdon, MD, PhD, Fan Lu, MD, PhD

PII:

S0002-9394(18)30394-5

DOI:

10.1016/j.ajo.2018.07.013

Reference:

AJOPHT 10582

To appear in: American Journal of Ophthalmology

Received Date: 28 March 2018

Revised Date: 18 June 2018

Accepted Date: 15 July 2018

Please cite this article as: Liang Y, Jiang J, Ou W, Peng X, Sun R, Xu X, Yang J, Hu C, Ye C, Congdon $\mathrm{N}$, Lu F, Effect of community screening on the demographic makeup and clinical severity of glaucoma patients receiving care in urban China, American Journal of Ophthalmology (2018), doi: 10.1016/ j.ajo.2018.07.013.

This is a PDF file of an unedited manuscript that has been accepted for publication. As a service to our customers we are providing this early version of the manuscript. The manuscript will undergo copyediting, typesetting, and review of the resulting proof before it is published in its final form. Please note that during the production process errors may be discovered which could affect the content, and all legal disclaimers that apply to the journal pertain. 


\section{ABSTRACT}

Purpose: To assess differences in clinical and demographic characteristics between glaucoma patients identified by community screening and those newly diagnosed in hospital in a Chinese setting.

Design: Prospective comparative cohort study.

Methods: 373 patients identified with glaucoma among 27,000 persons undergoing community screening were enrolled as the Screening group. The Clinic group consisted of 119 consecutively-presenting, newly-diagnosed glaucoma patients in hospital. Primary outcome: mean deviation (MD), visual field index (VFI) and pattern standard deviation (PSD) on Humphrey Field Analyzer, and intraocular pressure (IOP). Disease severity was categorized into five stages based on MD.

Results: $89.6 \%$ (328/373) of Screening Group patients had IOP < $21 \mathrm{mmHg}$, compared to $48.7 \%(58 / 119)$ in the Clinic group ( $\mathrm{P}<0.001)$. The Mean VFI, MD and PSD were $76.4 \pm 23.8 \%,-9.7 \pm 7.3 \mathrm{~dB}$, and $6.4 \pm 3.4 \mathrm{~dB}$ in the Screening group; and significantly worse in the Clinic group: $44.1 \pm 32.0 \%,-19.8 \pm 9.5 \mathrm{~dB}$, and $7.6 \pm 3.1 \mathrm{~dB}(\mathrm{P}<0.001$ for $\mathrm{MD}$ and VFI, $\mathrm{P}=0.001$ for PSD). Nearly three-quarters of Screening patients had Early or Moderate visual field loss (monocular), while nearly half of Clinic patients had severe loss at the time of diagnosis. Screening patients were significantly more likely to be older $(\mathrm{P}<0.001)$ and female $(\mathrm{P}<0.001)$ than Clinic patients.

Conclusion: Glaucoma patients detected through community screening had significantly milder damage, and were more likely to include under-served groups (women, elderly) than those newly diagnosed in a clinic in this setting. Comparison with population studies suggests that cases of glaucoma with IOP $<21 \mathrm{mmHg}$ are severely under-ascertained in China, which may be improved by screening. 
Effect of community screening on the demographic makeup and clinical severity of glaucoma patients receiving care in urban China

Short title: Glaucoma Screening in Urban China

Yuanbo Liang ${ }^{1,2}, \mathrm{MD}, \mathrm{PhD}$, Junhong Jiang ${ }^{1,3}$, MD, Wen Ou ${ }^{1}$, MD, Xianyao Peng ${ }^{1,3}$, MD, Ruizhu Sun ${ }^{l}$, MD, Xiang Xu ${ }^{l}$, MD, Juanyuan Yang ${ }^{l}$, MD, Cheng $H u^{l}$, MD, Cong Ye ${ }^{l}$, MB, PhD, Nathan Congdon ${ }^{2,4,5} \mathrm{MD}, \mathrm{PhD}$, Fan $\mathrm{Lu}^{l}$, MD, PhD

1. The Eye Hospital, School of Ophthalmology and Optometry, Wenzhou Medical University, Wenzhou, Zhejiang, China.

2. Centre for Public Health, Queen's University Belfast, UK.

3. Ningbo Eye Hospital, Ningbo, Zhejiang, China.

4. Division of Preventive Ophthalmology, Zhongshan Ophthalmic Center, Sun Yat-sen University, Guangzhou, China.

5. Orbis International, New York USA.

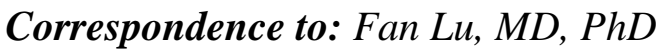

The Eye Hospital, School of Ophthalmology and Optometry, Wenzhou Medical University, Wenzhou, Zhejiang, China.

No. 270 West College Road, Wenzhou, Zhejiang, China, 325027.

Phone:086-577-88067961Ｅmail:lufan@mail.eye.ac.cn

Conflict of interest: The authors have no conflicts of interest with regard to the article

Financial Support: This study was supported by Wenzhou Medical University Research Fund. No. QTJ13009 and Zhejiang Province Health Innovation Talents project. No. 2016025. Prof Congdon is supported by the Ulverscroft Foundation, UK.

Manuscript length: 4706 words, 3 tables, 2 figures. Abstract: 250 words. 


\section{INTRODUCTION}

Glaucoma is the second-leading cause of blindness after cataract in both China and the world. ${ }^{1,2}$ With the aging of the world's population, and the steadily-rising global Cataract Surgical Rate (CSR), ${ }^{3,4}$ the relative importance of glaucoma as a cause of vision loss will continue to increase.

Carefully-done clinical trials have shown that early detection and lowering of intraocular pressure (IOP) delays onset ${ }^{5}$ and progression ${ }^{6-8}$ of glaucoma, thus preserving visual function. Due to the asymptomatic nature of early glaucoma, 50-90\% of patients are unaware of their disease in population studies. ${ }^{9-14}$ Serious and irreversible damage is common in many low-resource settings at the time of diagnosis. ${ }^{12,15-17}$ Severe visual impairment caused by glaucoma can significantly reduce quality of life among those affected, causing an un-necessary burden to both the individual and to society. $^{18,19}$

Screening for glaucoma may be a useful approach to identify cases at an early stage and reduce visual impairment and blindness. However, there has been debate about whether screening detects glaucoma at earlier stages of visual field loss. ${ }^{20,21}$ The study by Grødum et al. indicated that glaucoma patients diagnosed through population screening had less severe visual field damage than self-selected glaucoma patients. ${ }^{20}$ By contrast, the Thessaloniki Eye Study ${ }^{21}$ did not find a significant difference in severity between previously-diagnosed and undiagnosed glaucoma. In its updated screening recommendations for glaucoma, the United States Preventative Task Force (USPTF) found insufficient evidence to recommend for or against screening adults for glaucoma. ${ }^{22,23}$ The sparsity of data on the potential value of glaucoma screening in low and middle-income countries (LMICs) is particularly pronounced. Screening may have other benefits as well: A previous study in rural China has demonstrated that outreach screening for cataract improves equity of access to care by increasing the proportion of female, older, less-educated and poorer patients when compared to those presenting spontaneously to clinic. However, no such data are currently available for glaucoma in LMIC settings.

The Wenzhou Glaucoma Screening Program was a government-supported project aimed at improving the detection rate of glaucoma in Wenzhou, southern China. The current study is designed to compare the clinical and demographic characteristics between glaucoma patients detected through a community screening ("Screening group") and glaucoma patients newly diagnosed in hospital ("Clinic group").

\section{METHODS}

\section{Screening Group}

The Wenzhou Glaucoma Screening Program was conducted in three districts of Wenzhou, China (Lucheng, Longwan and Ouhai), between March 2014 and September 2015. Targeted subjects were residents of these districts aged 50 years or older, having specific risk factors for glaucoma: myopia, diabetes, or family history of glaucoma. This study adhered to the Declaration of Helsinki, and the study protocol was approved by the Ethics Committee of the Wenzhou Medical University. Oral informed consent was obtained from all subjects prior to participation. 
The screening program was advertised in the target communities one week in advance by means of local radio, leaflets, mobile phone short message (SMS) and posters. The screening team included one publicist, four ophthalmic technicians and one ophthalmologist, who was responsible to review and interpret the examination results. The team and all equipment were transported from the Eye Hospital of Wenzhou Medical University to the screening venues, in local community centers. Screening in each community lasted from 2 to 5 days, and a total of 71 communities were covered in the three districts.

All subjects participated voluntarily in the screening program. Participants were requested to provide personal information such as name, date of birth, gender, and telephone number. After enrollment and acquisition of informed consent, all subjects received a primary ophthalmic examination at the screening center, including assessment of visual acuity (VA), IOP measurement, non-mydriatic fundus photography, and slit-lamp examination. Distance VA was assessed with each individual's habitual refraction (if available) in each eye separately (Xinkang XK-100 logarithmic visual acuity chart, Xinkang Co., Wenzhou, China) at a distance of 5 meters. IOP was measured by non-contact tonometry (Canon Tx-20 Full Auto Tonometer, Canon Inc., Tokyo, Japan) three times in each eye and the median value recorded as the final reading. Monoscopic fundus color photographs were obtained (NIDEK Non-Mydriatic AFC-330 auto fundus camera, NIDEK Inc., Tokyo, Japan or Canon CR-2 Digital Retinal Camera, Canon, Inc., Tokyo, Japan) without pupil dilation. The anterior segment of the eye was assessed by handheld slitlamp (Kanghua SLM-6M, Kanghua Inc.,

Chongqing, China). All fundus photographs were reviewed by a single, fellowship-trained glaucoma specialist (YBL) to identify glaucoma suspects (see below for definitions).

Glaucoma suspects were invited to the Clinical and Epidemiological Eye Research Center of The Eye Hospital of Wenzhou Medical University for a comprehensive ophthalmologic examination, including visual acuity testing, IOP measurement, slit-lamp examination, visual field testing (Humphrey Field Analyzer IIi (HFA IIi, Carl Zeiss Meditec Inc., Dublin, CA) and fundus photography (VISUCAM 200, Carl Zeiss Meditec Inc., Dublin, CA). All examinations were performed by a team of certified technicians.

Subjects whose diagnosis of primary glaucoma was confirmed by the study glaucoma specialist (YBL) were included in all analyses as the Screening group. If both eyes met inclusion criteria (see below), the worse eye was chosen. Subjects with secondary glaucoma, previous laser or incisional surgery of the retina, history of acute angle closure and/or other diseases potentially affecting the visual field were excluded.

\section{Clinic Group}

During the screening period (March 2014 to September 2015), consecutive outpatients newly diagnosed as primary glaucoma by the study glaucoma specialist (YBL) were recruited as outpatient group from the Eye Hospital of Wenzhou Medical University. Additional inclusion criteria (1) Undergoing visual field testing in the Clinical and Epidemiological Eye Research Center at the Eye Hospital of Wenzhou Medical University, (2) Resident of Zhejiang province, and (3) Non-participant in the Wenzhou Glaucoma Screening Program. Subjects with secondary glaucoma, 
previous laser or incisional surgery of the retina, history of acute angle closure and/or other diseases potentially affecting the visual field were excluded. If both eyes met the inclusion criteria, the worse eye was chosen for analysis. Data on Clinic Group patients were retrieved from medical records at the time of diagnosis.

\section{Diagnosis and Definitions (In both groups)}

Glaucoma suspect: If one or more of the following characteristics were present in either eye, a participant was considered to be a glaucoma suspect:

1) Cup-disc ratio (CDR) $\geq 0.65$, CDR asymmetry $\geq 0.2$ or neural rim tissue $\leq 0.1$;

2) Optic disc hemorrhage on either disc photography or clinical examination;

3) Localized or diffuse retinal nerve fiber layer (RNFL) defects.

Glaucoma was defined by the presence in either eye of glaucomatous optic neuropathy (optic disc hemorrhage, RNFL defect, CDR $>0.7$, asymmetry $>0.2$ or neuroretinal rim width $<0.1$ ), with a reliable corresponding visual field defect. ${ }^{24}$ All glaucoma cases in the clinic setting were required to be newly-diagnosed.

Glaucoma Severity: Glaucomatous eyes were categorized into five stages based on the mean deviation of the HFA II visual field test in the worst-affected eye: ${ }^{25}$ early glaucoma (Better than $-6.00 \mathrm{~dB}$ ), moderate glaucoma ( -6.01 to $-12.00 \mathrm{~dB})$, advanced glaucoma $(-12.01$ to $-20.00 \mathrm{~dB})$, severe glaucoma ( $-20.01 \mathrm{~dB}$ or worse), and end-stage glaucoma/blind (Unable to perform visual field testing for reasons of poor vision).

Blindness and Visual impairment: These were defined according to World Health Organization (WHO) criteria. Blindness: presenting VA $<6 / 120$ Moderate and Severe visual impairment: presenting VA $\leq 6 / 18$ and $\geq 6 / 120{ }^{26}$

\section{Statistical Analysis}

Statistical analyses were performed using Statistical Analysis System software version 9.1.3 for Windows (SAS Institute, Cary, North Carolina, USA). Comparisons between the Screening and Clinic groups were done using the Student's t-test for continuous variables, and Chi-Square Tests for categorical variables, adjusting for age and sex using generalized linear models and logistic regression. The proportion of patients with IOP $<21 \mathrm{mmHg}$ in each group was calculated. Visual acuity results were converted into logarithm of the minimum angle of resolution (logMAR) values. The visual field indices used for statistical analysis included mean deviation (MD), visual field index (VFI), and pattern standard deviation (PSD). All statistical tests were two-sided, and a $\mathrm{p}$ value of $<0.05$ was considered significant. For patients unable to perform visual field testing due to severe glaucoma, the lowest mean deviation (MD) score $(-30 \mathrm{~dB})$ was recorded. ${ }^{27}$

\section{RESULTS}

From March 2014 to September 2015, 27,144 individuals were screened in 71 communities. Among 2704 (9.96\%) glaucoma suspects identified during community screening, 1539 (56.9\%) underwent further ophthalmologic examination at the Clinical and Epidemiological Eye Research Center. 
Though all glaucoma suspects received a written recommendation for a further ophthalmologic examination, $43.1 \%$ glaucoma suspects did not present for further detailed examinations. Subjects presenting for full examination did not differ from those defaulting with regard to sex, IOP, CDR and VA. (Table 1)

Among these, 376 (24.4\%) were diagnosed as having primary glaucoma, and 373 of these (99.2\%, 218 women [58.4\%], mean age $67.4+/-7.6$ years, 373 eyes) were recruited into the Screening group. The remaining patients were excluded due to a history of acute angle closure $(n=3)$. During the same period, 119 consecutive newly-diagnosed primary glaucoma patients (46 women [38.7\%], mean age $60.4+/-13.7$ years, 119 eyes) without history of acute angle closure were recruited to the Clinic group.

Screening group patients were significantly more likely to be women $(58.4$ versus $38.7 \%, \mathrm{P}<$ $0.005)$ than Clinic group patients, and were significantly older $(67.4+/-7.62$ versus $60.4+/-13.7$ years, $\mathrm{P}<0.001)$. (Table 2) The mean and median IOP in Screening group patients $(15.4 \pm-5.0$ $\mathrm{mmHg}$ and $14.9 \pm-5.0 \mathrm{mmHg}$ ) was significantly lower than that for the Clinic group $(23.8 \pm 12.6$ $\mathrm{mm} \mathrm{Hg}$ and 20.2 $\pm-12.6 \mathrm{mmHg}, \mathrm{P}<0.001)$, and the large majority $(328 / 373=89.6 \%)$ of Screening group patients had IOP < $21 \mathrm{mmHg}$, compared to only $48.7 \%$ (58/119) of the Clinic group. (Figure 1 , Table 3) Median logMAR VA in the Clinic group $(0.42 \pm 0.33)$ was significantly worse than that for the Screening group $(0.26 \pm 0.24, \mathrm{P}<0.001)$, and significantly more Clinic group $(12 / 119=10.1 \%)$ patients had presenting VA $<6 / 120$ (blindness) in the worse-seeing eye than in the Screening group $(6 / 373=1.6 \%, \mathrm{P}<0.001)$. The Mean VFI, MD, and PSD were all significantly better in the Screening group $(76.4 \pm 23.8 \%,-9.7 \pm 7.3 \mathrm{~dB}$, and $6.4 \pm 3.4 \mathrm{~dB}$ respectively) than in the Clinic group $(44.1 \pm 32.0 \%,-19.8 \pm 9.5 \mathrm{~dB}$, and 7.6 $\pm 3.1 \mathrm{~dB}$ respectively, $\mathrm{P}<0.001$ for $\mathrm{MD}$ and $\mathrm{VFI}, \mathrm{P}=0.001$ for PSD).Worse VA, higher IOP and worse visual field defects in the Clinic compared to the Screening group persisted after adjustment for age and sex using regression modeling. (Table 3).

Figure 2 depicts the severity of visual field defects in the worse-seeing eye by group (graded in order of worsening damage as Early, Moderate, Advanced, Severe and End-stage). Most (72.7\%) Screening group patients had early $(36.8 \%)$ or moderate $(35.9 \%)$ glaucomatous visual field defects while nearly half of the Clinic group had severe (43.5\%) glaucomatous visual field defects (P $<0.001)$.

\section{DISCUSSION}

Screening group patients had significantly less severe glaucomatous damage compared to those in the Clinic group, as measured by visual acuity, prevalence of blindness, severity of visual field indices and overall visual field grade. This is consistent with the report from Grødum et al, ${ }^{20}$ who compared 402 glaucoma patients identified by population screening with 354 newly-diagnosed in routine clinical practice. Their Screening group had significantly lower mean IOP, better visual fields and a lower incidence of bilateral disease than the Clinic group. The VF defects of the Clinic group in the current study (Mean MD $-19.8 \mathrm{~dB}$ ) were worse than those reported by Grødum et al $(-16.2 \mathrm{~dB}, \mathrm{P}<0.01$, PSD not reported). This may be associated with significantly greater damage at the time of diagnosis than open-angle glaucoma, ${ }^{28,29}$ or lower rates of early detection of glaucoma in China as a developing country. ${ }^{11,12,30,31}$ Among our Screening group patients, $72.7 \%$ had early or moderate glaucomatous visual field defects, consistent with results of Early Manifest Glaucoma 
Trial (EMGT), which also employed a population-based sample. ${ }^{32}$

The Thessaloniki Eye Study ${ }^{21}$ compared differences in VF defects between previously-diagnosed and previously-undiagnosed cases of open angle glaucoma, according to Advanced Glaucoma Intervention Study (AGIS) visual field scores. In contrast to our findings, they did not observe a significant difference $(7.2 \pm 5.8$ versus $6.4 \pm 4.5, \mathrm{P}=0.830)$ between the two groups. The Thessaloniki study defined previously-diagnosed patients as those who had glaucoma and positive response to at least one of following questions: family history of glaucoma, history of prior diagnosis of OHT, or history of medical or surgical treatment for glaucoma or OHT. It is possible that previously-diagnosed patients ascertained in a population setting may represent a less severely-affected group than patients identified in clinic, as patients with more severe disease and more regular follow-up are more likely to be ascertained in the latter setting.

Broman et $\mathrm{al}^{27}$ have estimated the mean annual rate of visual field progression in the worse-affected eyes of Chinese glaucoma patients as $-1.56 \mathrm{~dB} / \mathrm{yr}$ (95\% CI: $-1.98,-1.18)$. This would suggest that Screening group patients were diagnosed 5.1 to 8.6 years earlier than Clinic patients in the current study. Our screening program resulted in detection of patients with MD 10 $\mathrm{dB}$ less severe than those newly-diagnosed in our clinic setting, which translates into significant differences in quality of life. ${ }^{33}$ Freeman et al and McKean-Cowdin et al that even mild visual field loss can worsen health-related quality of life. ${ }^{34,35}$ With less severe VF defect and a mean age of $67.4+/-7.6$ years, it is expected that with appropriate management of IOP, the large majority of Screening group patients can maintain good visual function throughout their lives. Early detection has implications for the healthcare system as well as individual patients. Screening and subsequent treatment could delay or retard glaucoma disease progression but may increase costs to the healthcare system. Further study is needed to evaluate the economic impact.

Nearly $90 \%$ of Screening group patients had IOP $<21 \mathrm{mmHg}$ at the time of diagnosis, compared to some $40 \%$ of the Clinic group. Chinese population-based studies have uniformly found that approximately $90 \%$ of glaucoma patients have IOP $<21 \mathrm{mmHg} .{ }^{13,36,37}$ It is our hypothesis that the disparity in IOP between Screening and Clinic groups in the current study reflects a particular failure of the Chinese healthcare system to detect and treat glaucoma patients with "normal" IOP. This is consistent with studies revealing limited knowledge about glaucoma among Chinese ophthalmologists, and a general tendency to equate "glaucoma" with "elevated pressure." 38,39 Given trial evidence that IOP-lowering treatment is beneficial in preventing field progression in patient with IOP in the normal range ${ }^{40}$, there is another potential benefit of glaucoma screening in this setting: the detection of glaucoma patients with IOP $<21 \mathrm{mmHg}$, who it appears are otherwise less likely to be detected and receive care. Implementation will depend on training Chinese ophthalmologists to offer IOP-lowering treatment for these patients, and possibly also the execution of clinical trials to examine the benefit of such treatment among Chinese subjects.

Screening patients were significantly older and more likely to be female than Clinic patients. This is consistent with previous studies of cataract outreach screening in rural China, ${ }^{41,42}$ and suggests that outreach screening programs can improve equity of access to eye care, if interventions can be found to maintain patients screening positive in long-term care. In many parts of China, as in 
other settings, women and the elderly are less likely to access healthcare, and redressing this imbalance can be an important function of outreach screening programs.

There are limitations of this study. Firstly, glaucoma patients were not subdivided into open and closed-angle glaucoma, due to our having found it impractical to perform gonioscopy on this large volume of patients in the screening setting. This limited our ability to assess the degree of glaucoma damage in different types of glaucoma, to facilitate comparison with other studies, but this was not in fact the main purpose of the current study. Secondly, despite all glaucoma suspects being recommended to attend a further ophthalmic examination, a substantial number (43\%) were lost to follow-up. This is typical of community screening programs, and in fact, much higher losses to follow-up have been reported in other settings. ${ }^{43}$ However, we found no significant differences between those suspects with and without follow-up in terms of sex, IOP, CDR and VA. Therefore, we believe that the glaucoma suspects enrolled in the current study are likely representative of suspects detected during community screening. Thirdly, the Clinic patients were recruited from a glaucoma specialist clinic, which might be expected to include more severely-affected patients. However, the glaucoma clinic in this case is the most common location for management of glaucoma patients and suspects at Wenzhou Medical University, making it the largest single source of such care in the area. It receives patients with a broad range of clinical presentations, including those determined ultimately not to have disease. Importantly, by restricting the Clinic wing of the study to newly-diagnosed patients, we reduced the tendency to select for more severely-affected patients. For these reasons, we feel that this cohort is generally representative of glaucoma patients receiving clinical care in this setting. Finally, we did not address the issue of cost-effectiveness of our screening program, which will be considered in a future publication.

In summary, the current report is one of the first to address the impact of large-scale community screening for glaucoma, targeting high risk subjects in a low and middle-income country setting. We demonstrated it was possible to detect glaucoma patients with $10 \mathrm{~dB}$ less damage than those newly-diagnosed in a clinic setting, and also found that the proportion of patients with IOP $<21$ $\mathrm{mmHg}$ was far closer to that reported for the population at large when compared to clinic patients. Finally, our program showed the potential to address gender and age inequities in access to eye care for glaucoma patients in this setting. Such screening strategies in China may help to delay visual field damage caused by glaucoma, prevent blindness and reduce the economic burden of glaucoma care. Their cost effectiveness remains to be determined in future studies. 


\section{Acknowledgments:}

FINANCIAL SUPPORT: Wenzhou Medical University Research Fund (QTJ13009), Zhejiang Province Health Innovation Talents Project. No. 2016025. Prof Congdon is supported by the Ulverscroft Foundation, UK.

FINANCIAL DISCLOSURES: The following authors have no financial disclosures: Yuanbo Liang, Junhong Jiang, Wen Ou, Xianyao Peng, Ruizhu Sun, Xiang Xu, Juanyuan Yang, Cheng Hu, Cong Ye, Nathan Congdon, Fan Lu.

OTHER ACKNOWLEDGEMENTS: None

All authors attest that they meet the current ICMJE criteria for authorship. 


\section{References}

1. Bourne RR, Stevens GA, White RA, et al. Causes of vision loss worldwide, 1990-2010: a systematic analysis. Lancet Glob Health. Dec 2013;1:e339-349.

2. Wong TY, Zheng Y, Jonas JB, et al. Prevalence and causes of vision loss in East Asia: 1990-2010. Br J Ophthalmol. May 2014;98:599-604.

3. $\quad$ Erie JC, Baratz KH, Hodge DO, Schleck CD, Burke JP. Incidence of cataract surgery from 1980 through 2004 : 25-year population-based study. J Cataract Refract Surg. Jul 2007;33:1273-1277.

4. Gollogly HE, Hodge DO, St Sauver JL, Erie JC. Increasing incidence of cataract surgery: population-based study. J Cataract Refract Surg. Sep 2013;39:1383-1389.

5. Kass MA, Heuer DK, Higginbotham EJ, et al. The Ocular Hypertension Treatment Study: a randomized trial determines that topical ocular hypotensive medication delays or prevents the onset of primary open-angle glaucoma. Arch Ophthalmol. Jun 2002;120:701-713; discussion 829-730.

6. Leske MC, Heijl A, Hussein M, Bengtsson B, Hyman L, Komaroff E. Factors for glaucoma progression and the effect of treatment: the early manifest glaucoma trial. Arch Ophthalmol. Jan 2003;121:48-56.

7. Comparison of glaucomatous progression between untreated patients with normal-tension glaucoma and patients with therapeutically reduced intraocular pressures. Collaborative Normal-Tension Glaucoma Study Group. Am J Ophthalmol. Oct 1998;126:487-497.

8. The Advanced Glaucoma Intervention Study (AGIS): 7. The relationship between control of intraocular pressure and visual field deterioration. The AGIS Investigators. Am J Ophthalmol. Oct 2000;130:429-440.

9. Leske MC, Connell AM, Schachat AP, Hyman L. The Barbados Eye Study. Prevalence of open angle glaucoma. Arch Ophthalmol. Jun 1994;112:821-829.

10. Shen SY, Wong TY, Foster PJ, et al. The prevalence and types of glaucoma in malay people: the Singapore Malay eye study. Invest Ophthalmol Vis Sci. Sep 2008;49:3846-3851.

11. Foster PJ, Oen FT, Machin D, et al. The prevalence of glaucoma in Chinese residents of Singapore: a cross-sectional population survey of the Tanjong Pagar district. Arch Ophthalmol. Aug 2000;118:1105-1111.

12. Dandona L, Dandona R, Srinivas M, et al. Open-angle glaucoma in an urban population in southern India: the Andhra Pradesh eye disease study. Ophthalmology. Sep 2000;107:1702-1709.

13. Liang YB, Friedman DS, Zhou Q, et al. Prevalence of primary open angle glaucoma in a rural adult Chinese population: the Handan eye study. Invest Ophthalmol Vis Sci. 2011;52:8250-8257.

14. Liang Y, Friedman DS, Zhou Q, et al. Prevalence and characteristics of primary angle-closure diseases in a rural adult Chinese population: the Handan Eye Study. Invest Ophthalmol Vis Sci. Nov 2011;52:8672-8679.

15. Tielsch JM, Sommer A, Katz J, Royall RM, Quigley HA, Javitt J. Racial variations in the prevalence of primary open-angle glaucoma. The Baltimore Eye Survey. Jama. Jul 17 1991;266:369-374.

16. Hattenhauer MG, Johnson DH, Ing $\mathrm{HH}$, et al. The probability of blindness from open-angle glaucoma. Ophthalmology. Nov 1998;105:2099-2104.

17. Zhong H, Li J, Li C, et al. The prevalence of glaucoma in adult rural Chinese populations of the Bai nationality in Dali: the Yunnan Minority Eye Study. Invest Ophthalmol Vis Sci. May 31 2012;53:3221-3225.

18. Traverso CE, Walt JG, Kelly SP, et al. Direct costs of glaucoma and severity of the disease: a multinational long term study of resource utilisation in Europe. Br J Ophthalmol. Oct 2005;89:1245-1249.

19. Lee PP, Walt JG, Doyle JJ, et al. A multicenter, retrospective pilot study of resource use and costs associated with severity of disease in glaucoma. Arch Ophthalmol. Jan 2006;124:12-19.

20. Grodum K, Heijl A, Bengtsson B. A comparison of glaucoma patients identified through mass screening and in 
routine clinical practice. Acta Ophthalmol Scand. Dec 2002;80:627-631.

21. Topouzis F, Coleman AL, Harris A, et al. Factors associated with undiagnosed open-angle glaucoma: the Thessaloniki Eye Study. Am J Ophthalmol. Feb 2008;145:327-335.

22. Ervin AM, Boland MV, Myrowitz EH, et al. AHRQ Comparative Effectiveness Reviews. Screening for Glaucoma: Comparative Effectiveness. Rockville (MD): Agency for Healthcare Research and Quality (US); 2012.

23. Screening for glaucoma: recommendation statement. Ann Fam Med. Mar-Apr 2005;3:171-172.

24. Foster PJ, Buhrmann R, Quigley HA, Johnson GJ. The definition and classification of glaucoma in prevalence surveys. Br J Ophthalmol. Feb 2002;86:238-242.

25. Mills RP, Budenz DL, Lee PP, et al. Categorizing the stage of glaucoma from pre-diagnosis to end-stage disease. Am J Ophthalmol. Jan 2006;141:24-30.

26. Media Centre, World Health Organization. Magnitude and causes of visual impairment. Fact Sheet no. 282. November 2004. Available at: http://www.who.int/mediacentre/factsheets/fs282/en/. Accessed December 17, 2007.

27. Broman AT, Quigley HA, West SK, et al. Estimating the rate of progressive visual field damage in those with open-angle glaucoma, from cross-sectional data. Invest Ophthalmol Vis Sci. Jan 2008;49:66-76.

28. Quigley HA, Broman AT. The number of people with glaucoma worldwide in 2010 and 2020. Br J Ophthalmol. Mar 2006;90:262-267.

29. Casson RJ, Newland HS, Muecke J, et al. Prevalence and causes of visual impairment in rural myanmar: the Meiktila Eye Study. Ophthalmology. Dec 2007;114:2302-2308.

30. Liang YB, Friedman DS, Zhou Q, et al. Prevalence of primary open angle glaucoma in a rural adult Chinese population: the Handan eye study. Invest Ophthalmol Vis Sci. 2011;52:8250-8257.

31. Song W, Shan L, Cheng F, et al. Prevalence of glaucoma in a rural northern china adult population: a population-based survey in kailu county, inner mongolia. Ophthalmology. Oct 2011;118:1982-1988.

32. Heijl A, Bengtsson B, Oskarsdottir SE. Prevalence and severity of undetected manifest glaucoma: results from the early manifest glaucoma trial screening. Ophthalmology. Aug 2013;120:1541-1545.

33. Weinreb RN, Khaw PT. Primary open-angle glaucoma. Lancet. May 22 2004;363:1711-1720.

34. Freeman EE, Munoz B, West SK, Jampel HD, Friedman DS. Glaucoma and quality of life: the Salisbury Eye Evaluation. Ophthalmology. Feb 2008;115:233-238.

35. McKean-Cowdin R, Wang Y, Wu J, Azen SP, Varma R. Impact of visual field loss on health-related quality of life in glaucoma: the Los Angeles Latino Eye Study. Ophthalmology. Jun 2008;115:941-948.e941.

36. Wang NL, Friedman DS, Zhou Q, et al. A population-based assessment of 24-hour intraocular pressure among subjects with primary open-angle glaucoma: the handan eye study. Invest Ophthalmol Vis Sci. 2011;52:7817-7821.

37. He M, Foster PJ, Ge J, et al. Prevalence and clinical characteristics of glaucoma in adult Chinese: a population-based study in Liwan District, Guangzhou. Invest Ophthalmol Vis Sci. Jul 2006;47:2782-2788.

38. Yan X, Liu T, Gruber L, He M, Congdon N. Attitudes of physicians, patients, and village health workers toward glaucoma and diabetic retinopathy in rural China: a focus group study. Arch Ophthalmol. Jun 2012;130:761-770.

39. Zhang Q, Cao K, Kang MT, et al. [The questionnaire survey on glaucoma diagnosis and treatment in China (2016)]. Zhonghua Yan Ke Za Zhi. Feb 11 2017;53:115-120.

40. The effectiveness of intraocular pressure reduction in the treatment of normal-tension glaucoma. Collaborative Normal-Tension Glaucoma Study Group. Am J Ophthalmol. Oct 1998;126:498-505.

41. Zhang M, Wu J, Li L, et al. Impact of cataract screening outreach in rural China. Invest Ophthalmol Vis Sci. Jan 
2010;51:110-114.

42. Baruwa E, Tzu J, Congdon N, He M, Frick KD. Reversal in gender valuations of cataract surgery after the implementation of free screening and low-priced high-quality surgery in a rural population of southern China. Ophthalmic Epidemiol. Mar-Apr 2008;15:99-104.

43. Quigley HA, Park CK, Tracey PA, Pollack IP. Community screening for eye disease by laypersons: the Hoffberger program. Am J Ophthalmol. Mar 2002;133:386-392. 
Figure 1. Frequency distribution curves for intraocular pressure in screened glaucoma patients and outpatients.

Figure 2. Stages of glaucomatous visual field loss in screened glaucoma patients and outpatients. Early defect (Better than $-6.00 \mathrm{~dB})$, Moderate defect ( -6.01 to $-12.00 \mathrm{~dB})$, Advanced defect $(-12.01$ to $-20.00 \mathrm{~dB}$ ), Severe defect ( $-20.01 \mathrm{~dB}$ or worse), and End-stage disease /Blind (Unable to perform Humphrey visual fields). 
Table 1. The characteristics of glaucoma suspects.

\begin{tabular}{cccc}
\hline & $\begin{array}{c}\text { Suspects with } \\
\text { follow-up } \\
(\mathrm{n}=1539)\end{array}$ & $\begin{array}{c}\text { Suspects without } \\
\text { follow-up } \\
\text { Female, No. (\%) }\end{array}$ & $\begin{array}{c}\text { P-value } \\
\text { (Comparing Suspects } \\
\text { with and without } \\
\text { follow-up) }\end{array}$ \\
\hline Age (years), mean(SD) & $625(60.1 \%)$ & $717(61.5 \%)$ & .447 \\
IOP (mmHg), mean(SD) & $14.4(0.12)$ & $69.8(0.3)$ & .369 \\
CDR, mean(SD) & $0.57(0.005)$ & $0.57(0.005)$ & .359 \\
VA, \% & & & .249 \\
$\geq 0.5$ & $64.5 \%$ & $60.7 \%$ & \\
$0.3 \sim 0.5$ & $16.8 \%$ & $19.1 \%$ & \\
$0.1 \sim 0.3$ & $13.7 \%$ & $14.9 \%$ & \\
$<0.1$ & $5.1 \%$ & $5.2 \%$ & \\
\hline
\end{tabular}

$\mathrm{SD}=$ standard deviation $; \mathrm{IOP}=$ intraocular pressure

$\mathrm{CDR}=$ cup-to-disc diameter ratio; $\mathrm{VA}=$ visual acuity; 
Table 2. Baseline characteristics of screened patients and outpatients.

\begin{tabular}{llll}
\hline & $\begin{array}{l}\text { Screening Group } \\
(\mathrm{n}=373)\end{array}$ & $\begin{array}{l}\text { Clinic Group } \\
(\mathrm{n}=119)\end{array}$ & $\begin{array}{l}\text { P-value } \\
\text { (Comparing Screening } \\
\text { and Clinic Group) }\end{array}$ \\
\hline Female, No. $(\%)$ & $218(58.4 \%)$ & $46(38.7 \%)$ & $<.001$ \\
Age (years), mean(SD) & $67.4(7.6)$ & $60.4(13.7)$ & $<.001$ \\
$<50$ years, No. $(\%)$ & $4(1.1 \%)$ & $24(20.2 \%)$ & \\
$50-59$ years, No. $(\%)$ & $50(13.4 \%)$ & $24(20.2 \%)$ & \\
$60-69$ years, No. $(\%)$ & $168(45.0 \%)$ & $43(36.1 \%)$ & \\
$\geq 70$ years, No. $(\%)$ & $151(40.5 \%)$ & $28(23.5 \%)$ & \\
\hline
\end{tabular}

$\mathrm{SD}=$ standard deviation; 
Table 3. Comparison of clinical characteristics between screened patients and outpatients.

\begin{tabular}{|c|c|c|c|c|}
\hline & $\begin{array}{l}\text { Screening Group } \\
(n=373)\end{array}$ & $\begin{array}{l}\text { Clinic Group } \\
(n=119)\end{array}$ & $\begin{array}{l}\text { Unadjusted } \\
\text { comparison } \\
\text { between } \\
\text { Groups }\end{array}$ & $\begin{array}{l}\text { Age and } \\
\text { sex-adjusted } \\
\text { comparison } \\
\text { between Groups }\end{array}$ \\
\hline IOP $(\mathrm{mmHg})$, mean(SD) & $15.4(5.0)$ & $23.8(12.6)$ & $<.001$ & $<.001$ \\
\hline VA (logMAR), mean(SD) & $0.26(0.24)$ & $0.42(0.33)$ & $<.001$ & $<.001$ \\
\hline CDR, mean(SD) & $0.69(0.14)$ & $0.80(0.09)$ & $<.001$ & $<.001$ \\
\hline $\mathrm{MD}(\mathrm{dB})$, mean $(\mathrm{SD})$ & $-9.7(7.3)$ & $-19.8(9.5)$ & $<.001$ & $<.001$ \\
\hline $\operatorname{PSD}(\mathrm{dB})$, mean(SD) & $6.4(3.4)$ & $7.6(3.1)$ & .001 & .003 \\
\hline VFI $(\%)$, mean $(\mathrm{SD})$ & $76.4(23.8)$ & $44.1(32.0)$ & $<.001$ & $<.001$ \\
\hline $\begin{array}{l}\text { Moderate and Severe visual } \\
\text { impairment, No. }(\%)\end{array}$ & $60(16.1 \%)$ & $39(32.8 \%)$ & $<.001$ & \\
\hline Blindness, No. (\%) & $6(1.6 \%)$ & $12(10.1 \%)$ & $<.001$ & \\
\hline IOP $<21 \mathrm{mmHg}$, No. $(\%)$ & $328(89.6 \%)$ & $58(48.7 \%)$ & $<.001$ & \\
\hline
\end{tabular}

$\mathrm{IOP}=$ intraocular pressure; $\mathrm{SD}=$ standard deviation; $\mathrm{VA}=$ visual acuity; $\mathrm{CDR}=$ cup-to-disc diameter ratio;

$\mathrm{MD}=$ mean deviation; $\mathrm{PSD}=$ pattern standard deviation; $\mathrm{VFI}=$ visual field index

IOP $\$$ : 7 treated outpatients who had IOP $<21 \mathrm{mmHg}$ were excluded from the IOP analyses.

Moderate and Severe visual impairment defined as presenting visual acuity $\leq 6 / 18$ and $\geq 6 / 120$.

Blindness defined as presenting visual acuity $<6 / 120$.

VA results*:18 patients (6 screened patients and 12 outpatients) were blind and 18 patients (13 screened patients and 5 outpatients) had no record of VA ,36 patients were excluded from the VA analyses.

VF results*: 5 patients' MD of VF test were substituted by $-30 \mathrm{~dB}$ and 10 unreliable results were excluded. 


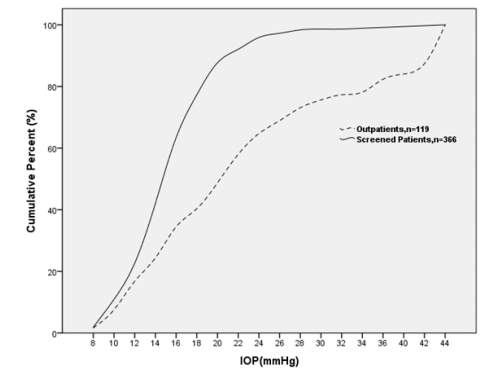




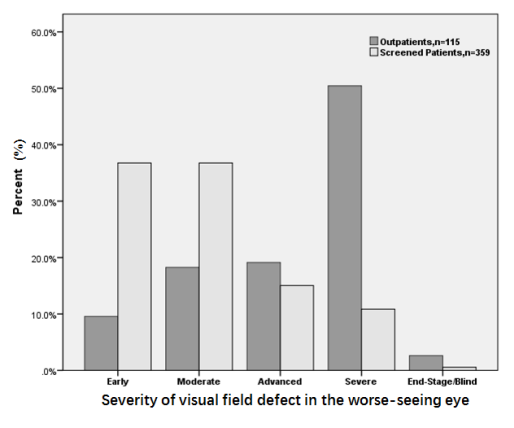


Compared to patients diagnosed in clinic, this large-scale community screening in China detects glaucoma patients $10 \mathrm{~dB}$ earlier, identifies normal-tension glaucoma patients who are otherwise missed and significantly improves gender equity. 